\title{
Amoxycillin Trihydrate Floating-Bioadhesive Drug Delivery System for Eradication of Helicobacter pylori: Preparation, In Vitro and Ex Vivo Evaluation
}

\author{
Narendar Dudhipala ${ }^{1}$, Arjun Narala ${ }^{1}$, Karthik Yadav Janga ${ }^{2}$ and Ramesh Bomma ${ }^{3 *}$ \\ ${ }^{1}$ University College of Pharmaceutical Sciences, Kakatiya University, Warangal, Telangana, India \\ ${ }^{2}$ Kakatiya Institute of Pharmaceutical Sciences, Warangal, Telangana, India \\ ${ }^{3}$ SRR College of Pharmaceutical Sciences, Elkathurthy, Karimnagar, Telangana, India
}

\begin{abstract}
The aim of the present investigation was to formulate and evaluate floating-bioadhesive tablets of amoxicillin trihydrate (ATFBT), to provide local action in the treatment of Helicobacter pylori (H. pylori) by prolonging the gastric residence time. The FBT were prepared by direct compression method using hydroxy propyl methyl cellulose (HPMC $\left.\mathrm{K}_{4} \mathrm{M}\right)$ / chitosan $(\mathrm{CH})$, carbopol (CP974P) / polymethacrylic acid (PMA) as release retarding agent / bioadhesive respectively, sodium bicarbonate $\left(\mathrm{NaHCO}_{3}\right)$ as a gas-former. The prepared tablets were evaluated for their physical characters such as drug content, in vitro buoyancy, swelling index, drug release and stability. Further, the bioadhesive strength (BS) was determined using porcine gastric mucosa. DSC studies indicate the compatibility of the drug and excipients used in the formulation. The floating lag time, total floating time, bioadhesive strength and swelling index of the optimized formulation (F7) was $32 \pm 2.7 \mathrm{sec}$, more than $12 \mathrm{~h}, 1.86 \pm 0.14 \mathrm{~N}$ and more than 3.5 respectively. Formulation (F7) was also found to be physically stable when stored at $40^{\circ} \mathrm{C} / 75 \% \mathrm{RH}$ for 3 months. The drug release profiles of all the formulations were fitted into various kinetic models. The optimized formulation followed the Peppas model $\left(r^{2}>0.99\right)$ with a non-Fickian diffusion mechanism $(n=0.625)$. From the results, a matrix floatingbioadhesive tablet incorporating an insoluble active substance such as amoxicillin trihydrate was developed for the successful eradication of $H$. pylori.
\end{abstract}

Keywords: Amoxycillin trihydrate; Floating-bioadhesive tablets; Helicobacter pylori; $\mathrm{HPMC}_{4} \mathrm{M}$; Drug release; Bioadhesvie strength

Abbreviations: ATFBT: Amoxicillin Trihydrate FloatingBioadhesive Tablets; BS: Bioadhesive Strength; HPMC: Hydroxy Propyl Methyl Cellulose; CH: Chitosan; CP974P: Carbopol; PMA: Polymethacrylic Acid

\section{Introduction}

Helicobacter pylorus (H. pylori) is a bacterium that causes chronic inflammation in the stomach and is a common cause of ulcers worldwide. It is also responsible for chronic gastritis, peptic ulcer disease and gastric malignancy in majority of healthy populations [1-3]. The treatment of $H$. pylori remains a challenging proposition; although it is highly sensitive to most antibiotics, difficult to eradicate from human body even with the current best therapies. Conventional formulations such as immediate release tablets are used for eradication therapy, but they do not remain in the stomach for longer time. Therefore, it is difficult to reach minimum inhibitory concentrations in the gastric mucus where $H$. pylori colonizes. The bioavailability and therapeutic efficiency of drugs was improved by many novel methods such as transdermal [4], iontophoretic, intranasal [5-7] and complexation technique [8] for poorly water soluble drugs. Bioadhesive floating drug delivery systems are also useful in this context. In order to extend the gastric residence period, gastro retentive drug delivery systems have been developed, which is an approach to prolong gastric residence time and also to provide site-specific drug release in the upper gastrointestinal tract (GIT) for local or systemic effects [9]. These include high density (sinking) systems, low density (floating) systems, mucoadhesive systems, swelling and expanding systems, modified shape systems, [10], floating-bioadhesive drug delivery systems [11] and other delayed gastric emptying devices which would improve the therapeutic effects of many drugs.
In case of floating drug delivery system (FDDS), drug remains buoyant in the stomach for a longer period of time without reducing the gastric emptying rate. This result in retardation of drug release at the desired rate from the system, an increased gastric retention time (GRT) and helps in better control of fluctuations in plasma drug levels [12]. But, the main drawback of FDDS is that it is effective only when the fluid level in the stomach is sufficiently high, which aids in the buoyancy of the dosage form [13]. This limitation can be overcome by using bioadhesive polymers which enable it to adhere to the mucous lining of the stomach wall [14]. Floating- bioadhesive drug delivery systems offer the advantages of increased contact time with stomach mucosa resulting in more effective absorption, improving the bioavailability of drugs with absorption window high in the stomach and proximal intestine and reduced dosing frequencies [13].

Previously, lectin conjugated multi particulate floating systems of clarithromycin for eradication of $H$. pylori was reported based on the mucoadhesive property of gastric mucosa [15]. Levofloxacin (single and mini floating tablets) was found to be a potential candidate for targeted drug delivery and are anticipated to be useful in the treatment of H. pylori [16].

*Corresponding author: Ramesh Bomma, SRR College of Pharmaceutical Sciences, Elkathurthy, Karimnagar, Telangana, India, Tel: 91-08727-281642 E-mail: rameshbommapharm@gmail.com

Received January 30, 2016; Accepted March 28, 2016; Published April 02, 2016

Citation: Dudhipala N, Narala A, Janga KY, Bomma R (2016) Amoxycillin Trihydrate Floating-Bioadhesive Drug Delivery System for Eradication of Helicobacter pylori: Preparation, In Vitro and Ex Vivo Evaluation. J Bioequiv Availab 8: 118-124. doi:10.4172/jbb.1000280

Copyright: () 2016 Dudhipala N, et al. This is an open-access article distributed under the terms of the Creative Commons Attribution License, which permits unrestricted use, distribution, and reproduction in any medium, provided the original author and source are credited. 
Amoxycillin trihydrate (AT) is a moderate-spectrum, bactericidal, $\beta$-lactam antibiotic used to treat bacterial infections caused by susceptible microorganisms. It is better absorbed from the upper part of GIT, following oral administration, with a half-life of $1 \mathrm{~h}-2 \mathrm{~h}$. AT is prescribed for the treatment of $H$. pylori induced peptic ulcers alone or in combination with other drugs for the eradiation from the human body [17]. Conventional oral dosage form of AT cannot bring out complete eradication of $H$. pylori [18]. The reason for the incomplete eradication of $\mathrm{H}$. pylori is probably due to the short residence time of antimicrobial agents in the stomach so that effective antimicrobial concentration cannot be achieved in the gastric mucousal layer or epithelial cell surfaces where $H$. pylori exist. Hence, an attempt was made to formulate floating-bioadhesvie tablets of AT.

The present investigation was focused on the development of AT floating-bioadhesive tablets (ATFBT) by direct compression method and evaluation for the physical characters such as drug release, floating properties, swelling index and ex vivo bioadhesion study. Physical stability of developed optimized formulation at $40^{\circ} \mathrm{C} \pm 2{ }^{\circ} \mathrm{C} / 75 \% \pm 5 \%$ $\mathrm{RH}$ for 3 months was to be studied.

\section{Materials}

Amoxicillin trihydrate (AT) was received as generous gift sample from M/s Aurobindo Pharma Ltd, Hyderabad, India. Hydroxypropyl methyl cellulose (HPMC $\left.\mathrm{K}_{4} \mathrm{M}\right)$, chitosan $(\mathrm{CH})$ was received as gift sample from Dr. Reddy's Labs, Hyderabad, India. Carbopol974P (CP974P) and Polymethacrylic acid were received as gift sample from M/s Aurobindo Pharma. Ltd., Hyderabad, India. Sodium bicarbonate, citric acid, microcrystalline cellulose (Avicel PH102), magnesium stearate (MS) and talc were purchased from S.D. Fine-Chem. Ltd., Mumbai, India. All other reagents used were of analytical grade.

\section{Methods}

\section{Preparation of AT floating-bioadhesive tablets}

The floating-bioadhesive tablets of AT (ATFBT) were developed by using $\mathrm{HPMC} \mathrm{K}_{4} \mathrm{M} / \mathrm{CH}$ or $\mathrm{CP} 974 \mathrm{P} / \mathrm{PMA}$ as release retarding agents / bioadhesive polymers. Direct compression method was used for the preparation of tablets. Sodium bicarbonate was used as effervescent base/gas generating agent to generate carbon dioxide [12]. All components of the formulation were sieved individually through sieve (mesh size 40). The components of the formulation were mixed thoroughly for $20 \mathrm{~min}$. Magnesium stearate (sieved through 60-mesh) was added into powder blend as a lubricant and the resultant mass was mixed for an additional $3 \mathrm{~min}$. Finally, the resultant powder mass obtained was compressed into tablets with $13 \mathrm{~mm}$ round punches at a hardness of $6 \mathrm{~kg} / \mathrm{cm}^{2}$ on 16 station punching machine (Cadmach,
Ahmedabad, India). The composition of tablet formulations is shown in Table 1.

\section{Evaluation of final blend}

The flow properties of granules (before compression) were characterized in terms of angle of repose, tapped density, bulk density, Carr's index and Hausner ratio [19].

\section{Evaluation of physicochemical properties}

The formulated tablets were evaluated for weight variation, thickness, crushing strength, friability, weight variation, buoyancy, dissolution studies and stability studies. Further, ex vivo bioadhesion studies were conducted using porcine gastric mucosa.

The prepared floating-bioadhesive tablets were evaluated for weight variation using 20 tablets (IP, 1996), hardness (Monsanto tester) using 6 tablets, thickness (Vernier calipers) using 6 tablets, friability (Roche friabilator) using 10 tablets, drug content using 10 tablets, buoyancy using 6 tablets and dissolution studies using 6 tablets. The results were expressed as mean \pm S.D (Table 2).

\section{Drug content uniformity}

Prepared tablets were accurately weighed and finely powdered by pestle in a mortar. A weighed portion of each powder equivalent to dose (500 mg) of prepared tablet, was transferred in to a volumetric flask and the drug was extracted with methanol as the solvent. The contents of the flask were sonicated for $10 \mathrm{~min}$, filtered and diluted suitably with $0.1 \mathrm{~N}$ $\mathrm{HCl}$ as the solvent. The samples were analyzed spectrophotometrically at $272 \mathrm{~nm}$ [20].

\section{Determination of in vitro buoyancy}

The buoyancy of RSFBT was determined in six replicates using United States Pharmacopoeia (USP) dissolution apparatus II (Electrolab, TDT-06T, Mumbai, India) in $900 \mathrm{ml}$ of $0.1 \mathrm{~N} \mathrm{HCl}$, maintained at $37^{\circ} \mathrm{C}$ $\pm 0.5^{\circ} \mathrm{C}$ with paddle rotation of $50 \mathrm{rpm}$ [21]. The FLT as well as TFT were determined visually. The time taken by the tablet to emerge onto surface of dissolution medium and the total time, the tablet remained buoyant on fluid surface were noted as FLT and TFT, respectively for all the formulations.

\section{Dissolution studies}

The dissolution of prepared ATFBT was studied in six replicates using USP dissolution apparatus II (Electrolab, TDT-06T, Mumbai, India). The dissolution medium was $900 \mathrm{~mL}$ of $0.1 \mathrm{~N} \mathrm{HCl}(\mathrm{pH} \mathrm{1.2)}$; temperature was maintained at $37^{\circ} \mathrm{C} \pm 0.5^{\circ} \mathrm{C}$ with a paddle rotation at $50 \mathrm{rpm} .5 \mathrm{~mL}$ aliquots were withdrawn at predetermined time intervals

\begin{tabular}{|c|c|c|c|c|c|c|c|c|c|c|}
\hline \multirow[b]{2}{*}{ Ingredient } & \multicolumn{10}{|c|}{ Formulation (mg) } \\
\hline & $\mathrm{F} 1$ & $\mathrm{~F} 2$ & F3 & $\mathrm{F} 4$ & F5 & F6 & F7 & F8 & F9 & F10 \\
\hline AT & 500 & 500 & 500 & 500 & 500 & 500 & 500 & 500 & 500 & 500 \\
\hline $\mathrm{HPMC} \mathrm{K}_{4} \mathrm{M}$ & 50 & 75 & 100 & 125 & - & - & - & - & - & - \\
\hline Chitosan & 25 & 25 & 25 & 25 & - & - & - & - & - & - \\
\hline Carbopol 974P & - & - & - & - & 25 & 50 & 75 & 100 & 75 & 75 \\
\hline Polymethacrylic acid & - & - & - & - & 25 & 25 & 25 & 25 & 50 & 75 \\
\hline Sodium bicarbonate & 85 & 85 & 85 & 85 & 85 & 85 & 85 & 85 & 85 & 85 \\
\hline Avicel pH 102 & 123 & 98 & 73 & 48 & 148 & 123 & 98 & 73 & 48 & 23 \\
\hline Talc & 8.5 & 8.5 & 8.5 & 8.5 & 8.5 & 8.5 & 8.5 & 8.5 & 8.5 & 8.5 \\
\hline Magnesium Stearate & 8.5 & 8.5 & 8.5 & 8.5 & 8.5 & 8.5 & 8.5 & 8.5 & 8.5 & 8.5 \\
\hline
\end{tabular}

Total weight of tablet equivalent to $800 \mathrm{mg}$ 


\begin{tabular}{|c|c|c|c|}
\hline Formulation & Carr's Index (\%) & Angle of repose & Hanseur's ratio \\
\hline F1 & 21.4 & $25.9^{\circ}$ & 1.12 \\
\hline F2 & 23.5 & $24.3^{\circ}$ & 1.13 \\
\hline F3 & 21.6 & $25.8^{\circ}$ & 1.16 \\
\hline F4 & 22.3 & $26.6^{\circ}$ & 1.13 \\
\hline F5 & 21.1 & $24.6^{\circ}$ & 1.16 \\
\hline F6 & 21.8 & $24.6^{\circ}$ & 1.17 \\
\hline F7 & 22.3 & $26.9^{\circ}$ & 1.15 \\
\hline F8 & 23.1 & $27.3^{\circ}$ & 1.13 \\
\hline F9 & 21.6 & $27.8^{\circ}$ & 1.16 \\
\hline F10 & 24.5 & $25.4^{\circ}$ & 1.14 \\
\hline
\end{tabular}

and replaced with $5 \mathrm{ml}$ of fresh dissolution medium each time [22]. Samples were filtered using membrane filter $(0.45 \mu \mathrm{m})$ and suitably diluted with dissolution medium wherever necessary and absorbance of the samples was measured at $\lambda_{\max } 272 \mathrm{~nm}$ by using double beam UVVisible spectrophotometer (ELICO, SL 210, India).

\section{Drug release kinetics}

The drug release profiles were subjected to different kinetic models to explain the release kinetics for ATFBT. In this study, the drug release profiles were subjected to zero-order, first-order [23], Higuchi [24] and Korsmeyer-Peppas kinetic models $[25,26]$. The goodness of fit was evaluated using the correlation coefficient values $\left(\mathrm{R}^{2}\right)$.

Zero-order: $\mathrm{F}=\mathrm{K}_{0} \mathrm{t}$; where $\mathrm{F}$ is the fraction of drug released at time $\mathrm{t}$, and $\mathrm{K}_{0}$ is the zero-order release constant.

First-order: $\ln (1-\mathrm{F})=-\mathrm{K}_{1} \mathrm{t}$; where $\mathrm{F}$ represents the fraction of drug released at time $t$, and $\mathrm{K}_{1}$ is the first-order release constant.

Higuchi model: $\mathrm{F}=\mathrm{K}_{\mathrm{H}}{ }^{1 / 2}$; where $\mathrm{F}$ represents the fraction of drug released at time $t$, and $\mathrm{K}_{\mathrm{H}}$ is the Higuchi constant.

Korsmeyer-Peppas model: $\mathrm{F}=\mathrm{K}_{\mathrm{P}} \mathrm{t}^{\mathrm{n}}$; where $\mathrm{F}$ represents the fraction of drug released at time $t, K_{p}$ is the rate constant and $n$ is the release exponent, indicative of the drug release mechanism. A value of $\mathrm{n} \leq$ 0.5 , indicates the Fickian release mechanism. The value of $\mathrm{n}$ between 0.5 and 1 is an indication of non-Fickian release mechanism (both diffusion controlled and swelling controlled). When, $\mathrm{n} \geq 1$, it is case-II transport and this involves polymer dissolution and polymeric chain enlargement or relaxation.

\section{Swelling studies}

The swelling behavior of the tablets was determined in triplicate. Initial weight $\left(\mathrm{W}_{0}\right)$ of the tablets was noted individually and placed separately in a glass beaker containing $200 \mathrm{ml}$ of $0.1 \mathrm{~N} \mathrm{HCl}$, maintained at $37^{\circ} \mathrm{C} \pm 0.5^{\circ} \mathrm{C}$. At regular time intervals, the tablets were removed and the excess surface liquid was carefully removed by means of a filter paper. The swollen matrix was then reweighed $\left(\mathrm{W}_{1}\right)$. The percentage swelling was calculated by using following equation.

$$
\text { Percentage swelling }=\frac{(\mathrm{W} 1-\mathrm{W} 0)}{\mathrm{W} 0} \times 100
$$

\section{Measurement of bioadhesive strength of the tablets}

Bioadhesive strength of the prepared tablets was measured on a modified physical balance [27]. The porcine gastric mucosa was obtained from slaughter house and was stored in phosphate buffer solution prior to the bioadhesion study. The mucosal membrane was excised by removing the underlying connective tissue and isotonic phosphate buffer (IPB) pH 6.6 was used as the moistening fluid. It was washed thoroughly with IPB pH 6.6 and then tied over to the protrusion in the teflon block using a thread. The block was lowered into the glass container filled with IPB $\mathrm{pH} 6.6$ at $37^{\circ} \mathrm{C} \pm 2^{\circ} \mathrm{C}$ such that the buffer just touched the sides of the stomach membrane. The two sides of the balance were made equal, before the study, by keeping $5.0 \mathrm{~g}$ weight on the right pan. The glass container was kept below the left hand side of the balance. The tablet was stuck onto the lower side of the hanging Teflon cylinder using either a little moisture or a double sided tape. The surface of the stomach membrane was blotted with a whattman filter paper and $25 \mu \mathrm{L}$ of IPB pH 6.6 was added to the stomach surface. This was done in order to obtain reproducible results. The $5.0 \mathrm{~g}$ weight from the right pan was removed. This lowered the Teflon cylinder along the patch over the stomach membrane with a weight of $5.0 \mathrm{~g}$. This was kept undisturbed for $2.0 \mathrm{~min}$. Then the weights on the right hand side were slowly added with an increment of $0.5 \mathrm{~g}$ till the tablet just separated from the stomach membrane surface. The excess weight on the right pan, that is, total weight minus $5.0 \mathrm{~g}$ was taken as a measure of the bioadhesive strength. The equipment was located in an air-conditioned room at $22^{\circ} \mathrm{C}$ and $60 \%$ relative humidity.

\section{Physical stability studies}

Physical stability studies were conducted according to International Conference on Harmonization ( $\mathrm{ICH}$ ) guidelines. The optimized formulation was enclosed in polyethylene bottle and placed in a desiccator containing saturated sodium chloride solution, which provided $75 \% \pm 5 \% \mathrm{RH}$. The desiccator was stored at $40^{\circ} \mathrm{C} \pm 2^{\circ} \mathrm{C}$ for 3 months [28]. At predetermined time intervals, the tablets were examined for hardness, drug content, buoyancy and drug release. Finally, the tablets were tested for any statistical difference using the Students unpaired t-test at $\mathrm{p}<0.05$.

\section{Drug-excipient compatibility study}

Differential scanning calorimetry (DSC): DSC analysis of pure drug, pure polymers, physical mixtures (1:1 ratio of drug: polymer) and optimized formulation were performed using Universal DSC instrument ((model DSC-60, Shimadzu, USA). Approximately $8 \mathrm{mg}$ $10 \mathrm{mg}$ of sample was taken in aluminum crucible and heated within a heating range of $40^{\circ} \mathrm{C}-300^{\circ} \mathrm{C}$, at a rate of $10^{\circ} \mathrm{C} / \mathrm{min}$ using dry nitrogen as the effluent gas, empty aluminum crucible was used as reference.

\section{Results and Discussion}

The floating bioadhesive tablets of AT were prepared by effervescent technique. Initially, concentration of gas-generating agent was optimized. Tablets with 9,10 and $12.5 \%$ of sodium bicarbonate were prepared and evaluated for floating lag time (FLT) and total floating time (TFT). Tablets with $9 \%$ showed $108 \mathrm{sec} \pm 6.4 \mathrm{sec}$ of FLT with $>12$ $\mathrm{h}$ of TFT, whereas with $10 \%$ showed $66 \mathrm{sec} \pm 2.4 \mathrm{sec}$ of FLT with $12 \mathrm{~h}$ TFT. But, in case of $12.5 \%$, FLT was less than $40.3 \mathrm{sec} \pm 2.6 \mathrm{sec}$ but TFT was less than $12 \mathrm{~h}$. Hence, sodium bicarbonate at $10 \%$ concentration was selected for preparation of floating-bioadhesive tablets of AT.

\section{Screening for polymer concentration}

Initially, formulation of ATFBT was developed with $\mathrm{HPMC} \mathrm{K}_{4} \mathrm{M}$ $(50,100$ and $125 \mathrm{mg})$ and carbopol $(50,75$ and $100 \mathrm{mg}$ ) individually and subjected to buoyancy studies. All the formulations floated within $80 \mathrm{sec}-90 \mathrm{sec} / 70 \mathrm{sec}-80 \mathrm{sec}$ in HPMC $\mathrm{K}_{4} \mathrm{M} /$ carbopol formulations respectively with TFT of $8 \mathrm{~h}-10 \mathrm{~h}$. Combination of HPMC $\mathrm{K}_{4} \mathrm{M}$ with $25 \mathrm{mg}$ of Chitosan resulted in floating lag time of $60 \mathrm{sec}-70 \mathrm{sec}$ and combination of carbopol with $25 \mathrm{mg}$ of PMA resulted in $40 \mathrm{sec}-60 \mathrm{sec}$ 
Citation: Dudhipala N, Narala A, Janga KY, Bomma R (2016) Amoxycillin Trihydrate Floating-Bioadhesive Drug Delivery System for Eradication of Helicobacter pylori: Preparation, In Vitro and Ex Vivo Evaluation. J Bioequiv Availab 8: 118-124. doi:10.4172/jbb.1000280

of FLT with TFT of more than $12 \mathrm{~h}$. As the combinations showed better buoyancy properties, they were formulated and further studied.

\section{Flow properties of pre-compressed powder}

The powder blends prepared for compression of tablets were evaluated for their flow properties (Table 2). Angle of repose was in the range of $23.6^{\circ}$ to $28.2^{\circ}$. Carr's index was found to be in the range of 12.55 to 15.49 and Hausner's ratio ranged from 1.143 to 1.181 . These values indicate that the prepared powder blends exhibited good flow properties.

\section{Characterization of floating tablets}

The floating-bioadhesive tablets of AT were prepared by direct compression method using combination of HPMC $\mathrm{K}_{4} \mathrm{M} /$ Chitosan (F1-F4), carbopol 947 / PMA (F5-F10) and lactose as a channelling agent. The physico-chemical characteristics are shown in Table 3. The weight variation was within the range of Indian pharmacopoeial specifications (IP, 1996). The hardness of different formulations was found to be between $6.19 \pm 0.41$ and $6.33 \mathrm{~kg} / \mathrm{cm}^{2} \pm 0.43 \mathrm{~kg} /$ $\mathrm{cm}^{2}$, indicating satisfactory mechanical strength. The thickness for different formulations was found to be in between $7.5 \mathrm{~mm}$ to 7.6 $\mathrm{mm}$. The friability was less than $1 \%$ for all the formulations, which is an indication of good mechanical resistance of the tablets. The drug content of all the batches varied in between $98.88 \% \pm 2.92 \%$ and $99.94 \%$ $\pm 1.84 \%$ indicating content uniformity in the prepared batches.

\section{In vitro buoyancy studies}

All the batches of tablets were prepared by effervescent technique. Sodium bicarbonate was used as a gas generating agent. Formulations F1-F4, prepared with HPMC $\mathrm{K}_{4} \mathrm{M} /$ Chitosan floated with a lag time of $58 \pm 1.8 \mathrm{sec}$ to $66.4 \pm 3.2 \mathrm{sec}$. Formulations F5-F10, prepared with carbopol 937 / PMA showed a floating lag of $32 \pm 2.7 \mathrm{sec}$ to $59.8 \pm$ $1.4 \mathrm{sec}$. Tablets of all formulations showed Table 4 good buoyancy with maximum floating lag time of $66.4 \mathrm{sec} \pm 3.2 \mathrm{sec}$. This is mainly due to evolution of carbon dioxide entrapped inside the hydrated polymeric matrices, resulting from the interaction between gas generating agent and dissolution medium $(0.1 \mathrm{~N} \mathrm{HCl})$, and this leads to lowering of density of matrices below $1 \mathrm{gm} / \mathrm{ml}$ enabling the matrices to float. At HPMC content of $20 \%$ or more, the particles of HPMC are close enough to permit a faster establishment of the gel layer, in a manner that the effect of different viscosities of the polymers and type of filler (soluble, insoluble or swellable) is minimized [29]. All formulations remained buoyant due to the presence of gas generating agent, for more than $12 \mathrm{~h}$ in dissolution medium $(0.1 \mathrm{~N} \mathrm{HCl}, \mathrm{pH} 1.2)$ [30].

\section{Dissolution studies}

The dissolution studies revealed that formulations F1and F2 (containing $50 \mathrm{mg}$ and $75 \mathrm{mg}$ of $\mathrm{HPMC} \mathrm{K} \mathrm{M}$ ) showed a release of $99.45 \%$ and $98.99 \%$, respectively, in $6 \mathrm{~h}$ and $8 \mathrm{~h}$ (Figure 1). Formulation F3 (100 mg of HPMC $\mathrm{K}_{4} \mathrm{M}$ ) showed maximum drug release of $97.74 \%$ in $12 \mathrm{~h}$. The variation in drug release was due to different polymer concentrations in all the four formulations. Formulation F1and F2 was unable to sustain the drug release for desired period of time but in case of formulation F3, 97.7\% of drug was released in $12 \mathrm{~h}$. All these four formulations floated for $12 \mathrm{~h}$. Formulation F4 failed to show required drug release profile. Formulation F3 showed the desired drug release profile and floated with a lag time of $66.4 \mathrm{sec}$, for these reasons, it was considered as best formulation among all the four formulations.

The difference in drug release might be due to the amount of gel layer formed around the tablets. At higher concentrations of

\begin{tabular}{|c|c|c|c|c|c|}
\hline $\begin{array}{l}\text { Formulation } \\
\text { code }\end{array}$ & $\begin{array}{c}\text { Weight } \\
\text { variation } \\
(\mathrm{mg})^{\mathrm{a}}\end{array}$ & $\begin{array}{l}\text { Hardness } \\
\left(\mathbf{k g} / \mathrm{cm}^{2}\right)^{\mathrm{b}}\end{array}$ & $\begin{array}{c}\text { Thickness } \\
(\mathrm{mm})^{\mathrm{b}}\end{array}$ & $\begin{array}{c}\text { Friability } \\
(\%)^{d}\end{array}$ & $\begin{array}{l}\text { Drug } \\
\text { Content } \\
(\%)^{c}\end{array}$ \\
\hline F1 & $800.2 \pm 2.4$ & $6.33 \pm 0.43$ & $7.76 \pm 0.16$ & 0.31 & $99.56 \pm 2.33$ \\
\hline F2 & $799.4 \pm 3.1$ & $6.15 \pm 0.38$ & $7.86 \pm 0.23$ & 0.27 & $99.74 \pm 1.83$ \\
\hline F3 & $798.2 \pm 2.2$ & $6.28 \pm 0.65$ & $7.76 \pm 0.24$ & 0.43 & $98.91 \pm 1.34$ \\
\hline F4 & $801.8 \pm 2.8$ & $6.21 \pm 0.62$ & $7.63 \pm 0.16$ & 0.37 & $98.85 \pm 2.43$ \\
\hline F5 & $802.2 \pm 2.4$ & $6.24 \pm 0.32$ & $7.68 \pm 0.25$ & 0.33 & $\begin{array}{c}98.88 \pm \\
2.928\end{array}$ \\
\hline F6 & $799.5 \pm 2.7$ & $6.19 \pm 0.41$ & $7.55 \pm 0.15$ & 0.26 & $99.69 \pm 0.98$ \\
\hline F7 & $799.2 \pm 1.7$ & $6.26 \pm 0.52$ & $7.65 \pm 0.06$ & 0.53 & $99.94 \pm 1.84$ \\
\hline F8 & $800.8 \pm 1.6$ & $6.31 \pm 0.62$ & $7.62 \pm 0.09$ & 0.18 & $99.24 \pm 1.45$ \\
\hline F9 & $801.9 \pm 1.9$ & $6.29 \pm 0.63$ & $7.56 \pm 0.06$ & 0.53 & $99.41 \pm 2.36$ \\
\hline F10 & $802.2 \pm 2.4$ & $6.23 \pm 0.41$ & $7.48 \pm 0.04$ & 0.19 & $99.77 \pm 2.72$ \\
\hline
\end{tabular}

Mean \pm SD: $a-n=20$, b- $n=6, c-n=3, d-n=10$

Table 3: Physical evaluation parameters.

\begin{tabular}{|c|c|c|}
\hline Formulation & Floating lag time (sec) & Floating time (h) \\
\hline F1 & $58 \pm 1.8$ & $>12$ \\
\hline F2 & $59.7 \pm 2.3$ & $>12$ \\
\hline F3 & $66.4 \pm 3.2$ & $>12$ \\
\hline F4 & $60.8 \pm 1.9$ & $>12$ \\
\hline F5 & $51.7 \pm 2.6$ & $>12$ \\
\hline F6 & $58.6 \pm 2.5$ & $>12$ \\
\hline F7 & $32 \pm 2.7$ & $>12$ \\
\hline F8 & $41.9 \pm 0.9$ & $>12$ \\
\hline F9 & $58.9 \pm 2.4$ & $>12$ \\
\hline F10 & $59.8 \pm 1.4$ & $>12$ \\
\hline
\end{tabular}

Table 4: Floating properties of prepared tablets.

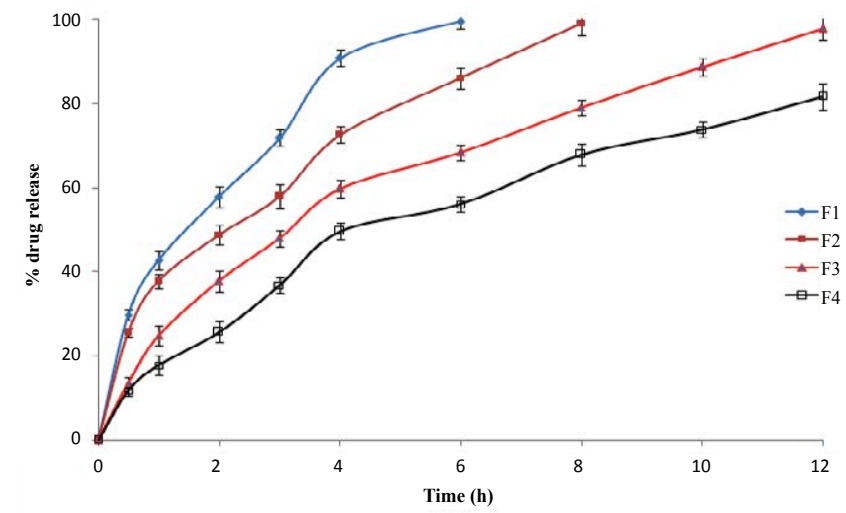

Figure 1: In vitro drug release of amoxicillin trihydrate from FBT (F1-F4) formulations.

polymer, it resulted in a greater amount of gel being formed. This gel increased diffusion length so that drug release was decreased. As the concentration of polymers was increased, the tablets could retain their physical integrity and the drug release was significantly extended.

Formulations F5-F8, composed of carbopol 974P (25 mg - 100 $\mathrm{mg}$ ) and PMA, showed a release of $98.75,98.85,99.83$ and $90.8 \%$ respectively. These variations in drug release were due to changes in polymer concentrations of the tablets. The main reason for retarded drug release is due to the presence of Carbopol 974P, which readily absorbs water and swells. In addition to its hydrophilic nature, cross- 
Citation: Dudhipala N, Narala A, Janga KY, Bomma R (2016) Amoxycillin Trihydrate Floating-Bioadhesive Drug Delivery System for Eradication of Helicobacter pylori: Preparation, In Vitro and Ex Vivo Evaluation. J Bioequiv Availab 8: 118-124. doi:10.4172/jbb.1000280

linked structure and insolubility in water makes the Carbopol $974 \mathrm{P}$ as a potential candidate for use in controlled release drug delivery systems.

Formulations F9 and F10 prepared with increased concentrations of PMA (50 mg and $75 \mathrm{mg}$ ) resulted in the floating lag time of $58.9 \pm$ $2.4 \mathrm{sec}$ and $59.8 \pm 1.4 \mathrm{sec}$, and the drug release was $97.87 \%$ and $89.95 \%$ in $12 \mathrm{~h}$. The results are shown in Figure 2.

In all the formulations, formulation F7 ( containing $75 \mathrm{mg}$ of carbopol and $25 \mathrm{mg}$ of PMA) met the desired drug release profile in 12 $h$ and floated with a lag time of $32 \pm 2.7 \mathrm{sec}$. It was, therefore, considered the best formulation among all the four formulations of this series.

\section{Release kinetics}

The data obtained from dissolution studies were fitted into different kinetic models viz., zero order, first order, Higuchi and Peppas model. The Higuchi plots were found to be linear as indicated by their high regression values $\left(\mathrm{R}^{2}=0.988\right.$ to 0.997$)$. To confirm the exact mechanism of drug release from these tablets, the data were fitted to Peppas model. Regression analysis was performed and $\mathrm{R}^{2}$ values were found in between 0.980 to 0.995 for different formulations. The values of the release exponent were in the range of 0.47 to 0.63 ; this suggested that the release of AT from FBT tablets followed non-Fickian transport mechanism. This means that water diffusion and also the polymer rearrangement played important role in the drug release. As can be seen in Table 5, release rate constants $(\mathrm{k})$ of the developed tablets were significantly different.

\section{Swelling studies}

The ability of hydration of the formulation is important because it effects on: (a) tablet buoyancy, and adhesion ability of swellable polymers and drug release kinetics. The percentage swelling obtained from the water uptake studies of the formulations is shown in Figures $3 \mathrm{~A}$ and $3 \mathrm{~B}$. Complete swelling was achieved at the end of $8 \mathrm{~h}$, then diffusion and erosion takes place. The formulation F4 and F8 shows higher swelling index compared to that of the other formulations. The swelling index of the tablets increased with an increase in the polymer concentration.

\section{Ex-vivo bioadhesion study}

Apart from buoyancy of the tablet, bioadhesive property could be an important property for gastro retentive drug delivery systems. The developed formulations contained CP 974P, which has bioadhesive property. HPMC polymers are also reported to have the bioadhesive property. The bioadhesive strength of the F7 formulation was found to be $1.86 \pm 0.14 \mathrm{~N}$.

\section{Physical stability studies}

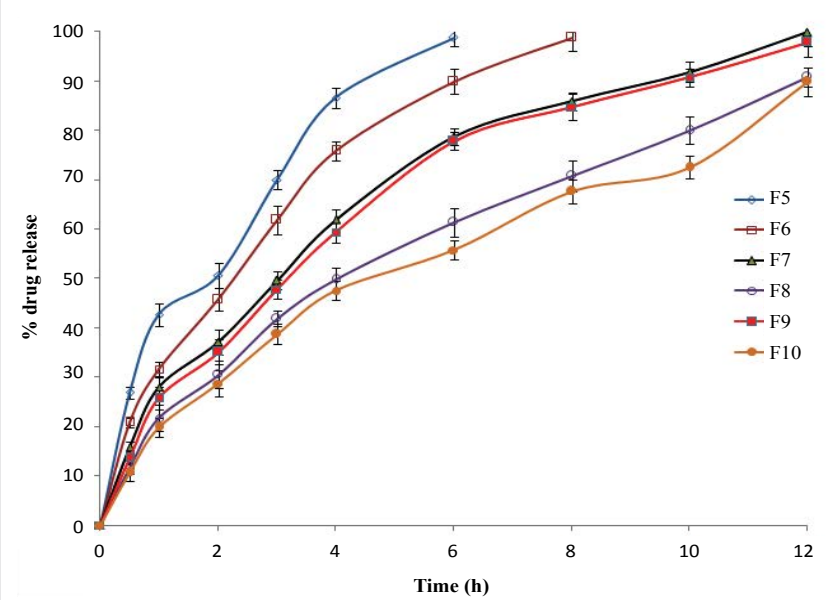

Figure 2: In vitro drug release of amoxicillin trihydrate from FBT (F5-F10) formulations.

\begin{tabular}{|l|c|c|c|c|c|}
\hline \multirow{2}{*}{ Formulation } & \multicolumn{3}{|c|}{$\mathbf{R}^{\mathbf{2}}$} & \multicolumn{2}{c|}{ Peppas } \\
\cline { 2 - 6 } & Zero order & First Order & Higuchi & $\mathbf{R}^{\mathbf{2}}$ & $\mathbf{n}$ \\
\hline F1 & 0.892 & 0.909 & 0.992 & 0.992 & 0.498 \\
\hline F2 & 0.909 & 0.876 & 0.997 & 0.995 & 0.479 \\
\hline F3 & 0.922 & 0.916 & 0.995 & 0.987 & 0.596 \\
\hline F4 & 0.937 & 0.994 & 0.989 & 0.991 & 0.623 \\
\hline F5 & 0.911 & 0.916 & 0.989 & 0.980 & 0.521 \\
\hline F6 & 0.915 & 0.930 & 0.992 & 0.994 & 0.579 \\
\hline F7 & 0.907 & 0.800 & 0.990 & 0.988 & 0.576 \\
\hline F8 & 0.946 & 0.970 & 0.995 & 0.993 & 0.62 \\
\hline F9 & 0.912 & 0.957 & 0.988 & 0.985 & 0.614 \\
\hline F10 & 0.952 & 0.935 & 0.988 & 0.992 & 0.632 \\
\hline
\end{tabular}

Table 5: Mathematical models and release kinetics of AT from FBT based on regression coefficient.
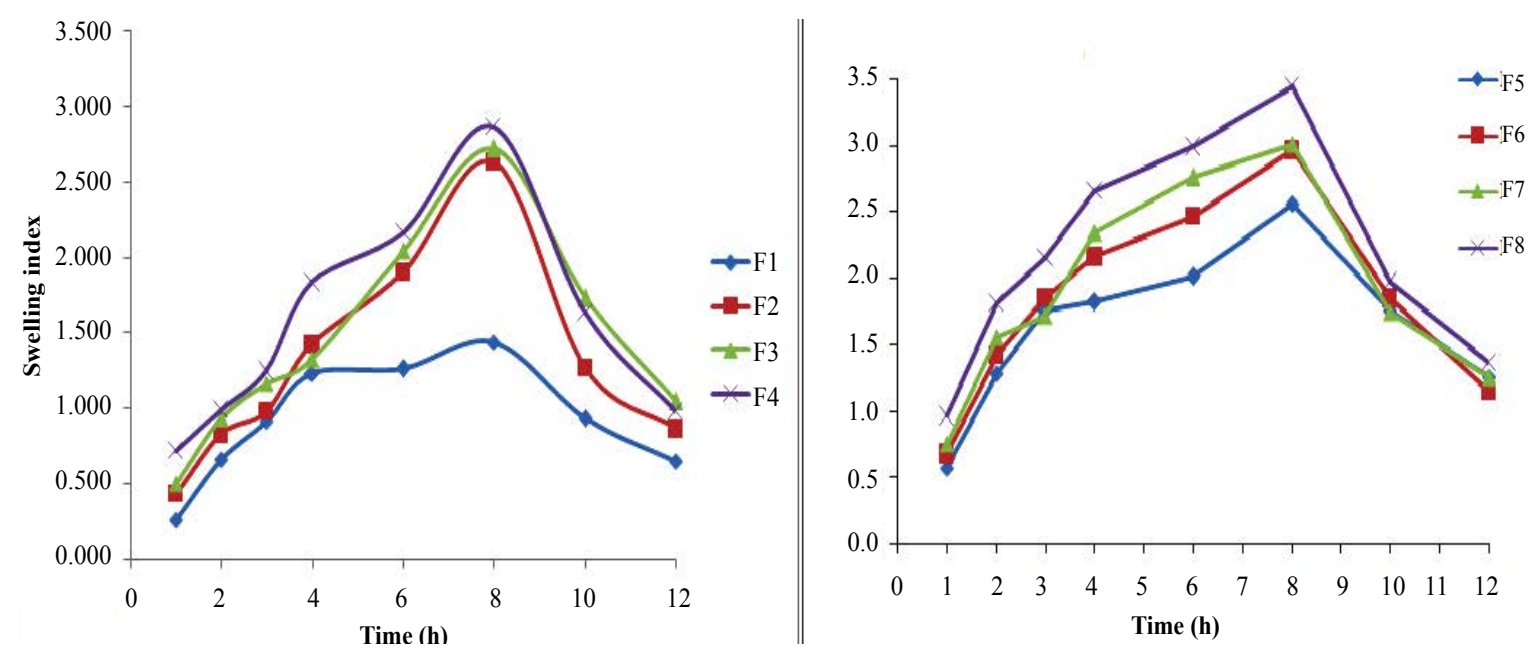

Figure 3: Swelling studies of amoxicillin FBT prepared with (A) $\mathrm{HPMCK}_{4} \mathrm{M}$ and (B) Carbopol. 
Citation: Dudhipala N, Narala A, Janga KY, Bomma R (2016) Amoxycillin Trihydrate Floating-Bioadhesive Drug Delivery System for Eradication of Helicobacter pylori: Preparation, In Vitro and Ex Vivo Evaluation. J Bioequiv Availab 8: 118-124. doi:10.4172/jbb.1000280

\begin{tabular}{|c|c|c|c|c|c|}
\hline Characteristic & 0 day $^{*}$ & $15^{\text {th }}$ day* & $30^{\text {th }}$ day $^{*}$ & $60^{\text {th }}$ day $^{*}$ & $90^{\text {th }}$ day $^{*}$ \\
\hline Hardness $\left(\mathrm{kg} / \mathrm{cm}^{2}\right)$ & $6.31 \pm 0.47$ & $6.42 \pm 0.71$ & $6.42 \pm 0.47$ & $6.06 \pm 0.70$ & $6.01 \pm 0.64$ \\
\hline Drug content (\%) & $99.89 \pm 1.82$ & $99.93 \pm 2.51$ & $99.88 \pm 2.74$ & $99.68 \pm 2.17$ & $99.48 \pm 12.02$ \\
\hline Floating lag time (s) & $32.11 \pm 3.21$ & $31.73 \pm 3.81$ & $30.89 \pm 2.84$ & $33.77 \pm 3.62$ & $33.89 \pm 3.71$ \\
\hline Duration of floating $(\mathrm{h})$ & $>12$ & $>12$ & $>12$ & $>12$ & $>12$ \\
\hline Drug released at $12 \mathrm{~h}(\%)$ & $99.89 \pm 2.43$ & $99.84 \pm 3.72$ & $99.73 \pm 2.84$ & $98.97 \pm 3.47$ & $99.10 \pm 3.84$ \\
\hline
\end{tabular}

*The difference was not statistically significant $(p>0.05)$

Table 6: Stability studies of ATFBT.

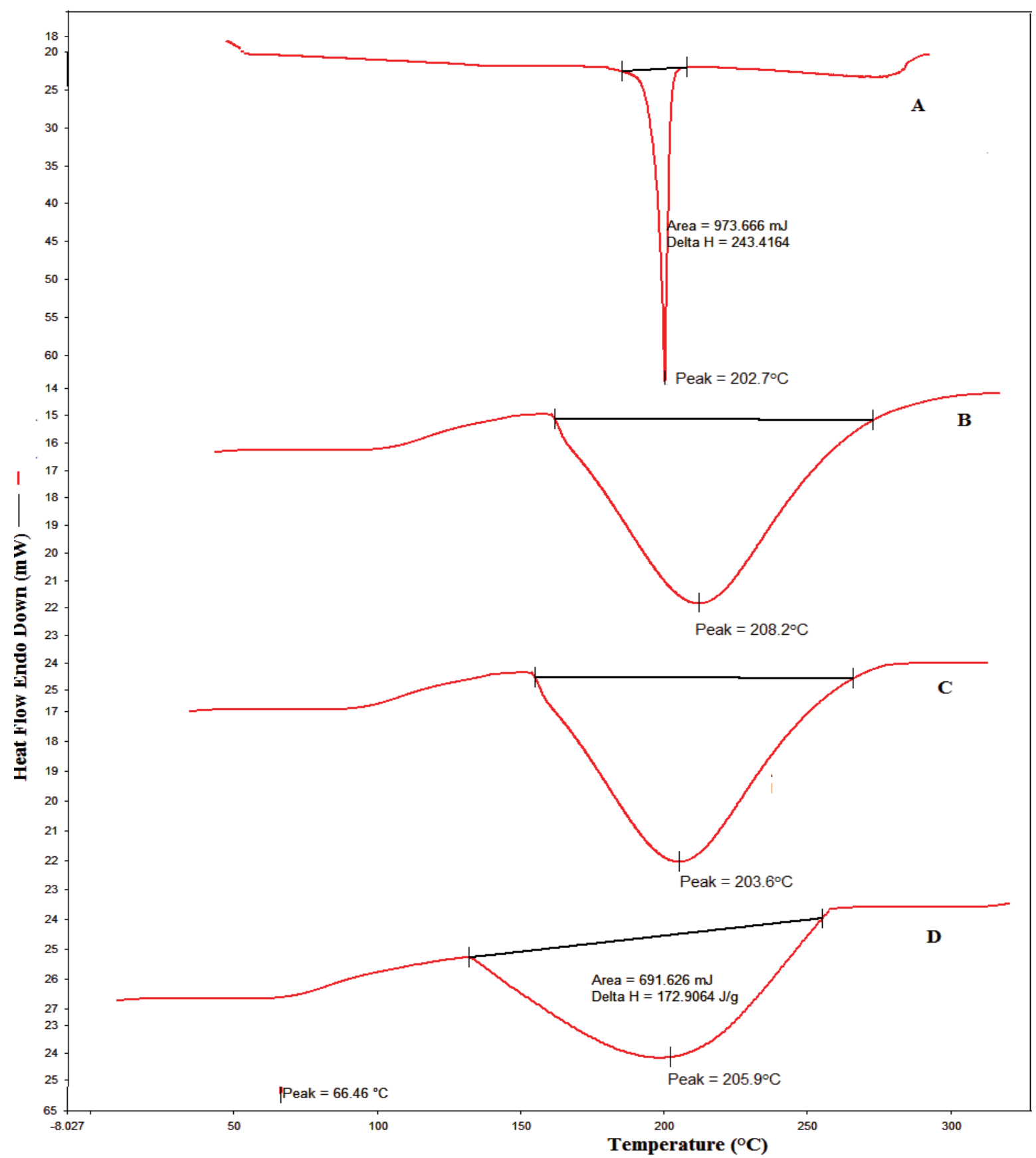

Figure 4: DSC thermograms of (A) pure drug, (B) physical mixture (1:1 ratio) of HPMC K $\mathrm{M}$ and drug, (C) physical mixture (1:1 ratio) of Carbopol and drug and (D) optimized formulation (F7). 
Citation: Dudhipala N, Narala A, Janga KY, Bomma R (2016) Amoxycillin Trihydrate Floating-Bioadhesive Drug Delivery System for Eradication of Helicobacter pylori: Preparation, In Vitro and Ex Vivo Evaluation. J Bioequiv Availab 8: 118-124. doi:10.4172/jbb.1000280

The optimized ATFBT was selected for stability studies. Before and after conducting the stability studies for 3 months, the results were analyzed by using Student's unpaired t-test. No significant difference ( $\mathrm{p}$ $>0.05$ ) was observed in the tablet hardness, drug content, buoyancy or dissolution (Table 6). Therefore, the ATFBT were found to be stable for at least 3 months under these storage conditions.

\section{Drug-excipient compatibility studies by differential scanning calorimetry}

The thermal properties of the drug and the mixture of drug and excipients are of important interest since this can help to assess the interaction among different components of the formulations. The DSC thermogram of pure drug (Figure 4) showed an endothermic peak (broader) at $202.7^{\circ} \mathrm{C}$ in a melting range of 208 to $215^{\circ} \mathrm{C}$. The $1: 1$ mixture of drug and HPMC $\mathrm{K}_{4} \mathrm{M}$ is having endothermic peak (broader) of drug at $208.2^{\circ} \mathrm{C}$. Similarly, $1: 1$ mixture of drug and carbopol showed an endothermic peak (broader) of drug at $203.6^{\circ} \mathrm{C}$, which was well preserved with slight changes in terms of broadening or a shifting of peak towards the lower temperature. This minor change in the melting endotherm of drug could be due to the mixing of drug and polymer, which lowered the purity of each component in the mixture and may not necessarily indicate potential incompatibility. The DSC thermogram of optimized formulation F7 showed an endothermic peak of drug at $205.9^{\circ} \mathrm{C}$ which was well preserved with slight change in terms of broadening of peak towards the higher temperature. From the results it was concluded that the drug had compatibility with polymers and other excipients used in the formulation.

\section{Conclusion}

Floating-bioadhesive tablets of AT were prepared using combination of HPMC K $\mathrm{K}_{4}$ M / Chitosan, and carbopol 947P / Polymethacrylic acid, a promising approach for treatment of $H$. pylori. Gas generating agent (sodium bicarbonate) is essential to achieve optimum buoyancy. The optimized formulation (F7) floated with a lag time of $32 \pm 2.7 \mathrm{sec}$ and floated for $12 \mathrm{~h}$. The non-Fickian diffusion was the release mechanism from these tablets. The formulation was stable up to 90 days and exhibited sufficient bioadhesive strength which was proven from ex vivo studies.

\section{Declaration of Interest}

Authors declare that there is no conflict of interest in this study.

\section{References}

1. Everhart JE (2000) Recent developments in the epidemiology of Helicobacter pylori. Gastroenterol Clin North Am 29: 559-578.

2. Peterson WL, Fendrick AM, Cave DR, Peura DA, Garabedian-Ruffalo SM, et al. (2000) Helicobacter pylori-related disease: guidelines for testing and treatment. Arch Intern Med 160: 1285-1291.

3. Megraud F, Lamouliatte H (1992) Helicobacter pylori and duodenal ulcer. Evidence suggesting causation. Dig Dis Sci 37: 769-772.

4. Yang Y, Manda P, Pavurala N, Khan MA, Krishnaiah YS (2015) Development and validation of in vitro-in vivo correlation (IVIVC) for estradiol transdermal drug delivery systems. J Control Release 210: 58-66.

5. Manda P, Sammeta SM, Repka MA, Murthy SN (2012) lontophoresis across the proximal nail fold to target drugs to the nail matrix. J Pharm Sci 101: 2392-2397.

6. Manda P, Angamuthu M, Hiremath SR, Raman V, Murthy SN (2014) lontophoretic drug delivery for the treatment of scars. J Pharm Sci 103: 1638-1642.

7. Manda P, Hargett JK, Vaka SR, Repka MA, Murthy SN (2011) Delivery of cefotaxime to the brain via intranasal administration. Drug Dev Ind Pharm 37: 1306-1310.
8. Popescu C, Manda P, Juluri A Janga KY, Cidda M, et al. (2015) Enhanced Dissolution Efficiency of Zaleplon Solid Dispersions via Modified ß-Cyclodextrin Molecular Inclusion Complexes. J Pharm Pharm Scien 1: 12-21.

9. Vyas SP, Khar RK (2006) Gastro retentive systems. In: Controlled drug Delivery. Vallabh Prakashan, Delhi, India 197-217.

10. Doodipala N, Palem RC, Reddy S, Rao Y (2011) Pharmaceutical development and clinical pharmacokinetic evaluation of gastroretentive floating matrix tablets of levofloxacin. Int J Pharm Sci Nanotech 4: 1463-1469.

11. Ponchel G1, Irache J (1998) Specific and non-specific bioadhesive particulate systems for oral delivery to the gastrointestinal tract. Adv Drug Deliv Rev 34: 191-219.

12. Kawashima Y, Niwa T, Takeuchi H, Hino T, Ito Y (1991) Preparation of multipleunit hollow microspheres (microballoons) with acrylic resin containing traniplas and their drug release characteristics (in vitro) and floating behaviour (in vivo). J Control Release 16: 279-289.

13. Chueh HR, Zia H, Rhodes CT (1995) Optimization of sotalol and bioadhesive extended-release tablet formulations. Drug Dev Ind Pharm 21: 1725-1747.

14. Chitnis VS, Malshe VS, Lalla JK (1991) Bioadhesive polymer synthesis, evaluation and application in controlled release tablets. Drug Dev Ind Pharm 17: 879-892.

15. Sunil KJ, Manmohan SJ (2009) Lectin conjugated gastroretentive multiparticulate delivery system of clarithromycin for the effective treatment of Helicobacter pylori. Molecular pharmaceutics 6: 295-304.

16. El-Zahaby SA, Kassem AA, El-Kamel AH (2014) Design and evaluation of gastroretentive levofloxacin floating mini-tablets-in-capsule system for eradication of Helicobacter pylori. Saudi Pharm J 22: 570-579.

17. Suleymanlar I, Tuncer M, Tugrul MS, Ertugrul C, Sarikaya M, et al. (1999) Response to triple treatment with omeprazole, amoxicillin, and clarithromycin for Helicobacter pylori infections in continuous ambulatory peritoneal dialysis patients. Adv Perit Dial 15: 79-81.

18. Cooreman MP, Krausgrill P, Hengels KJ (1993) Local gastric and serum amoxicillin concentrations after different oral application forms. Antimicrob Agents Chemother 37: 1506-9.

19. Hadi MA, Babu VL, Pal N (2012) Formulation and evaluation of sustained release matrix tablets of glimepiride based on combination of hydrophilic and hydrophobic polymers. J Appl Pharm Sci 2:101-107.

20. Giang DT, Hoang VD (2010) Comparative Study of RP-HPLC and UV Spectrophotometric techniques for the Simultaneous determination of Amoxicillin and Cloxacillin in Capsules. J Young Pharm 2: 190-195.

21. Rosa M, Zia H, Rhodes $T$ (1994) Dosing and in-vitro testing of a bioadhesive and floating drug delivery system for oral application. Int J Pharm 105: 65-70.

22. Narendar Reddy D, Chinna Reddy P, Sunil R, Madhusudan Rao Y (2012) Development of floating matrix tablets of Ofloxacin and Ornidazole in combined dosage form: in vitro and in vivo evaluation in healthy human volunteers. International J Drug Deli 4:462-469.

23. Wagner JG (1969) Interpretation of percent dissolved-time plots derived from in vitro testing of conventional tablets and capsules. J Pharm Sci 58: 1253-1257.

24. Higuchi T (1963) Mechanism of sustained-action medication. Theoretical analysis of rate of release of solid drugs dispersed in solid matrices. J Pharm Sci 52: 1145-1149.

25. Korsmeyer R, Gurny R, Peppas N (1983) Mechanisms of solute release from porous hydrophilic polymers. Int J Pharm 15:25-35

26. Peppas NA (1985) Analysis of Fickian and non-Fickian drug release from polymers. Pharm Acta Helv 60: 110-111.

27. Gupta A, Garg S, Khar RK (1993) Measurement of bioadhesive strength of muco-adhesive buccal tablets: design of an in vitro assembly. Indian drugs 30:152- 155.

28. Köllmer M, Popescu C, Manda P, Zhou L, Gemeinhart RA (2013) Stability of benzocaine formulated in commercial oral disintegrating tablet platforms. AAPS PharmSciTech 14: 1333-1340.

29. Alderete ME, Villafurete- Robles $L$ (1997) Influence of the viscosity grade and the particle size of HPMC on metronidazole release from matrix tablets. Eur $\mathrm{J}$ Pharm Biopharm 43: 173-78.

30. Jaimini M, Rana AC, Tanwar YS (2007) Formulation and evaluation of famotidine floating tablets. Curr Drug Deliv 4: 51-55. 